\title{
Manipulatives and Multiplicative Thinking
}

\author{
Chris Hurst ${ }^{1 *}$, Chris Linsell ${ }^{2}$ \\ ${ }^{1}$ Curtin University, AUSTRALIA \\ ${ }^{2}$ University of Otago, AUSTRALIA \\ *Corresponding Author: c.hurst@curtin.edu.au \\ Citation: Hurst, C. and Linsell, C. (2020). Manipulatives and Multiplicative Thinking. European Journal of \\ STEM Education, 5(1), 04. https:// doi.org/10.20897/ejsteme/5808
}

Published: September 7, 2020

\begin{abstract}
This small study sought to determine students' knowledge of multiplication and division and whether they are able to use sets of bundling sticks to demonstrate their knowledge. Manipulatives are widely used in primary and some middle school classrooms, and can assist children to connect multiplicative concepts to physical representations. Qualitative data were generated from semi-structured interviews with 32 primary and middle school children aged nine to eleven years. Participants were asked to work out the answer to multiplication and division examples and explain their thinking using bundling sticks. Results suggest that the majority of participant students may have a limited knowledge of aspects of the multiplication process and even less knowledge of the division process. The study also identified that many of the students appeared uncomfortable and/or unfamiliar with using bundling sticks and a number of them had difficulty in using bundling sticks to explain the multiplication and division processes. We conclude that manipulatives such as bundling sticks do not magically lead children to mathematical learning but are sufficiently powerful to warrant teachers familiarising themselves with how manipulatives can be used to develop conceptual understanding.
\end{abstract}

Keywords: procedural, conceptual, multiplicative, manipulatives

\section{INTRODUCTION}

Multiplicative thinking is one of the 'big ideas' of mathematics and is widely acknowledged as underpinning much of the mathematics learned beyond the early and middle years of primary school (Siemon, Bleckly, \& Neal, 2012). It is a complex set of inter-related ideas ranging from equal groups problems, inverse relationship between multiplication and division, multiplicative relationships in place value, and proportional reasoning (Siemon, Beswick, Brady, Clark, Faragher, \& Warren, (2015). Most students do not fully understand until they are well into their early secondary school years (Siemon, Breed, Dole, Izzard, \& Virgona, 2006). Students who continue to think additively find it difficult to progress beyond early mathematical concepts (Devlin, 2008) and it is incumbent on them to reconceptualise their thinking to fully understand multiplicative concepts (Wright, 2011). The level at which students understand these concepts may depend on the way they are taught and whether they have been encouraged to think conceptually, and in a relational and connected way, as opposed to learning procedurally and having only an instrumental view (Skemp, 1976). Teaching from a conceptual standpoint is likely to involve the use of manipulatives to support the later use of procedures and algorithms (Swan \& Marshall, 2010). This paper considers the role of manipulatives in teaching aspects of multiplicative thinking and also looks at the use of manipulatives as a tool for enabling teachers to assess students' knowledge of certain multiplicative concepts. 


\section{LITERATURE REVIEW}

\section{Manipulatives - Some Background}

Manipulatives have been variously described as physical or concrete objects or materials that can be handled. Van de Walle, Karp, and Bay-Williams (2013, p. 24) also included pictures and drawings and stated that "Manipulatives are physical objects that students and teachers can use to illustrate and discover mathematical concepts, whether made specifically for mathematics (e.g., connecting cubes) or for other purposes (e.g., buttons)".

Laski, Jor'dan, Daoust, \& Murray (2015, p. 1) said that manipulatives are "used to demonstrate a mathematics concept or to support the execution of a mathematical procedure". This is a point that will discussed later when considering results from the study. Swan and Marshall (2010, p. 14) defined a manipulative as "an object that can be handled by an individual in a sensory manner during which conscious and unconscious mathematical thinking will be fostered". They also added that manipulatives have "the potential to lead to an awareness and development of concepts and ideas linked with mathematics" (2010, p. 14). Their use of the word 'potential' is important as it infers that the extent to which such concept development occurs is dependent on the quality of the teaching and teacher knowledge. Swan and Marshall (2010) also indicated that virtual manipulatives should be withheld until children have experienced working with real objects.

The use of manipulatives in mathematics is not new and has been in vogue to various degrees for over a hundred years. Maria Montessori was one of the first mathematics educators to develop manipulatives for use with specific mathematical concepts (Laski et al., 2015). Montessori used manipulatives such as 'golden bead materials' to represent the Base 10 number system to teach place value, relative magnitude of numbers, and operations with numbers up to 10000 (Laski et al., 2015). During the 1950s and 1960s, Jean Piaget said that children's learning developed through concrete and pictorial stages, to the abstract. Specifically, they progress through a 'concrete operational' stage of learning, which prompted an increase in the use of manipulatives. This is notably similar to what was proposed by Jerome Bruner (Reys, Lindquist, Lambdin, Smith, Rogers, Falle, Frid, S. \& Bennett, 2012). Bruner's work gave rise to the concrete $>$ semi-abstract $>$ abstract learning sequence with a strong focus on the use of manipulatives. Specifically, Bruner developed a framework of stages through which children develop, beginning with the enactive stage (manipulation of real-world objects), and followed by the iconic stage based on representation of pictures, and the symbolic stage involving manipulation of symbols (Reys, et al., 2012). This was also facilitated by educators such as Georges Cuisenaire and Zoltan Dienes with the development of their Cuisenaire Rods and Multi-base Arithmetic Blocks (MABs) respectively. Cuisenaire Rods can be used to develop various concepts such as fraction, ratio, and proportion. MABs are most commonly used to build representations of numbers to four digits, and to develop the concepts of trading up and down when operating with numbers. MABs have individual units marked on them whereas Cuisenaire Rods do not. (Furner \& Worrell, 2017). Bundling sticks or popsticks are another extremely useful model for developing place value understanding. Van de Walle et al. (2013) describe them as an example of a groupable model as bundles can be bound together and undone. Bundling sticks were used in this study for that reason.

\section{Effective and Ineffective Use of Manipulatives}

Several prominent mathematics education researchers (Baroody, 1989; Ball, 1992; Ma, 1999) have written about manipulatives and urged caution in the way in which they are regarded. In his short but seminal paper, Baroody $(1989$, p. 4) stated that manipulatives "must be used judiciously and cautiously for good results" and that there is no guarantee that student learning will follow from their use. He posed two criteria which he said teachers should consider when planning to use manipulatives - does the manipulative have meaning for students because it connects with their existing knowledge, and does its use require students to reflect and think? Baroody (1989) suggested that, in order to determine whether or not the criteria are met, teachers need to observe their students at work to see if they followed the designated procedure or if they used a different method. Further to that, he suggested that teachers have students use their manipulative-based procedure to solve word problems and justify their solutions" (Baroody, 1989, p. 4). Ball (1992) took a similar stance in debunking the idea that manipulatives could somehow magically teach children. She noted that "manipulatives - and the underlying notion that understanding comes through the fingertips - have become part of educational dogma" and that teachers are encouraged to think that the use of manipulatives will lead to children coming to correct conclusions (Ball, 1992, p. 17). Baroody and Ball wrote their respective pieces over 25 years ago and their views no doubt reflected the great faith placed in manipulatives at the time.

$\mathrm{Ma}$ (1999) made similar points and described effective practice as being when teachers held class discussions after the use of manipulatives enabling them to explicitly construct the links between the interactions with the manipulative and the related symbolic procedures. Ma also noted that such discussions would likely give rise to questions that would deepen students' understanding of the mathematics but that would ultimately depend on the 
extent and quality of the teacher's content knowledge. Ma (1999, p. 26) made a particularly evocative comment about this - "A good vehicle, however, does not guarantee the right destination. The direction that students go with manipulatives depends largely on the steering of their teacher".

More recently, Roberts (2007, p. 9) echoed Ball in saying that there was nothing magical about manipulatives and that their power rested "in the careful orchestration of the task by the teacher and thoughtful reflection by the students". Again, this requires sound teacher knowledge in order to not only identify the appropriate manipulative to use for representing a particular concept, but to explicitly link the representation in the form of the manipulative to the concept. Laski et al. (2015) also noted manipulatives are merely physical representations of concepts, that abstract thinking is needed to understand the concept, and that the teacher's role is critical. By using the physical resource and the abstract concept together over a period of time, "it allows for an understanding of the two to coevolve" (Laski et al., 2015, p.2).

Puchner, Taylor, O'Donnell and Fick (2010) described a study of lessons at multiple grade levels from Year K to Year 8. In the Year Six lesson, students were asked to use manipulatives (arrays, base ten blocks) to work out the solution to a two-digit by two-digit multiplication example. Most students were unable to do so but knew how to use the standard algorithm and solved the problems that way. Hence there was no point in using manipulatives because they had already worked out the answer. Puchner et al. (2010, p. 321) explained it this as an example of ineffective manipulative use saying that

"The manipulative was turned into an end in and of itself, rather than a tool leading to better understanding. This likely occurred because of the deeply embedded focus in U.S. mathematics teaching on the procedure and the product".

Furthermore, Puchner et al. noted that teachers find the use of manipulatives appealing but attempt to use them with traditional procedural teaching methods. The result, they claimed, is that such lessons are likely to be ineffective. Puchner et al., (2010, p. 315) stated that

"Teachers often use manipulatives in a procedural manner, instructing students to apply a manipulative in a particular manner to obtain the correct answer. Such use obstructs rather than helps conceptual learning".

Other comments they made also align with those made by Ball and Baroody in that teachers often assume that a manipulative will automatically create an internal representation for students and that they find it hard to understand why students fail to form a clear understanding. Puchner et al. (2010, p. 314) then allude to a considerable issue in saying that "the reason teachers experience poor results when attempting to use manipulatives may be because effective use of manipulatives is more difficult than most realize". This seems to be something of a dilemma because teachers often cite poor results with using manipulatives as a reason for not using them.

\section{Principles for Manipulative Use}

Laski et al. (2015) made a number of important observations about how manipulatives should be used. They proposed four principles for 'maximizing the effectiveness of manipulatives' which reflect what others have said. These principles involve the consistent use over time, characterized by a transition from concrete to abstract, avoidance of manipulatives which have distracting features or closely resemble everyday objects, and explicitly connecting the manipulative to the concept being developed. They suggested that the more basic the manipulative the better. That is, a manipulative that is "stripped of all irrelevant perceptual features - then it helps children direct all of their attention to thinking about its relation with the mathematics concept it represents" (Laski et al., p. 5).

Delaney (2010) stated that the most effective way of using manipulatives was to combine teacher demonstration with students physically handling them. He said that "A resource which facilitates demonstration and interaction mediates discussion in powerful ways" (Delaney, 2010, p. 82). Teachers are able to explain and demonstrate but also to listen to students, interpret their responses, and see what level of knowledge is developing. This is supported by the findings of Carbonneau, Marley, and Selig (2013) in that greater effect sizes resulted when the use of manipulatives was accompanied by extensive instructional guidance rather than when they were used with low levels of guidance. Similarly, Van de Walle et al., (2013, p. 26) said that unless students are engaged in conversation about the mathematical goal, "the manipulative is not serving as a tool for developing the concept".

Boggan, Harper, and Whitmire (2010, p. 3) reinforced what was said by Puchner et al. (2010) and others in that appropriate choice of manipulatives was critical and must match the teaching objectives surrounding the concept being developed but also that "Children must understand the mathematical concept being taught rather than simply moving the manipulatives around [and] explicit instruction and scaffolding of supports is necessary". In order to bring this about, Cope (2015) stated the importance of teachers having the pedagogical training required to make effective use of manipulatives. As Swan and Marshall (2010, p. 16) said, "unless teachers have a clear understanding 
of how manipulatives assist children learn, they are likely to make only token use of them which may be detrimental to learning".

\section{Teacher Beliefs about Manipulatives}

In reviewing the work of Golafshani (2013), Furner and Worrell (2017) noted how teachers reported various 'disabling factors' for using manipulatives. Disabling factors included lack of time to prepare, lack of knowledge of multiple uses of manipulatives, lack of confidence and time to practice, difficulty with classroom management, and administrative support for teacher training. Earlier, Pushner et al. (2010) had said that teachers regarded time investment and poor results as factors that lead to non-use. Furner \& Worrell also noted various beliefs of teachers about why they used manipulatives. Some of the reasons were to provide a change of pace, a reward, a visual model for introducing concepts, providing reinforcement of enrichment, and to make it more fun.

'Teachers seemed to distinguish between 'real math' and 'fun math'. 'Real math' referred to lessons where they taught rules, procedures and algorithms to their students through textbooks, and 'fun math' was used when teachers described parts of their lesson where students were utilizing manipulatives" (Furner \& Worrell, 2017, p. 12).

This is quite concerning and seems to indicate that some teachers did not see that manipulatives have a real purpose in teaching concepts. Furner \& Worrell (2017, p. 13) added that

"Teachers who believe manipulatives are just used for a change of pace, reward or privilege or fun are not going to genuinely incorporate manipulatives and the concepts they were meant to convey into their lessons".

The implicit message that students would receive is that manipulatives are akin to 'toys' and have little mathematical value.

Swan and Marshall (2010) found similar sentiments when they surveyed some 820 teachers about the advantages of using manipulatives. The highest response was for the category that included 'Heighten interest, helped engage students, enjoyment, fun, motivation' (191), followed by 'Visual aid, assist in concrete visualisation' (188). 135 said 'Provide hands-on learning' and 126 said 'Build better understanding'. In response to what could be termed 'higher order categories', only 61 said 'Help children grasp concepts' and 36 said 'Can be used to introduce concepts'. Similarly, only 27 said 'Teachers can more easily note what the child is thinking' and 23 said 'Encouraged oral language'. The higher order comments did not attract as many comments as the relatively lower order comments such as fun, enjoyment, visual aid etc. This aligns well with the work of Furner \& Worrell about why teachers use manipulatives. It seems that a relatively small proportion of teachers see that manipulatives can be used to develop conceptual understanding.

Earlier work by Perry and Howard (1994) reported that the use of manipulatives was favoured more by teachers of Year 4 and below. They considered that this is likely due to the belief that Piaget's 'concrete operational' stage is completed by the age of ten or eleven years and that manipulatives are not needed after that age. As well, Perry and Howard (1997, p. 29) found that "As students grow older, many have a perception that is 'babyish' to use manipulatives". They also noted a common perception that Years 5 and 6 are preparation years for secondary school, where manipulatives are unlikely to be used, so their use diminishes in upper primary classes. This is generally supported by the findings of Swan and Marshall (2010) who asked teachers how often they used manipulatives. The responses for 'daily' or 'several times a week' ranged from $100 \%$ of Pre-primary teachers and $96 \%$ of Year 1 teachers to $54 \%$ of Year 5 teachers and $48 \%$ of Year 6 teachers.

\section{Conceptual/Relational Understanding v. Procedural/Instrumental Knowledge}

In his seminal paper, Skemp (1976, p. 89) discussed the differences between relational and instrumental understanding, noting that the latter is difficult to equate with 'understanding' at all as it more akin to "rules without reasons" whereas relational understanding is "knowing both what to do and why". For the purpose of this paper, relational understanding is equated with 'conceptual understanding' and 'connected knowledge' while instrumental knowledge is equated with 'procedural knowledge'. Skemp (1976, p. 92) went on to outline several advantages of relational understanding, one being that "it is more adaptable to new tasks".

Researchers (Hiebert, 1999; Puchner et al. 2010) have stated that students who have learned and practiced a procedure or algorithm, which they may not understand, are less likely to want to understand conceptually the underpinning mathematics. Mason, Stephens, and Watson (2009) view procedural and conceptual knowledge as intertwined rather than as alternatives. They suggest that although procedures are important in mathematics, recalling and using them without conceptual knowledge places too large a load on memory. They refer to this intertwined knowledge as an "appreciation of mathematical structure" (Mason et al., 2009, p. 12) and argue that 
relationships between mathematical ideas can be used for determining how appropriate a procedure is for solving a particular problem. From this perspective, procedural knowledge has to be appreciated in relation to the mathematical structure and context of the problem. These observations seem to point to the benefits of teaching conceptually rather than just focusing on procedures.

\section{Multiplicative Thinking}

Multiplicative thinking is considered to be one of the 'big ideas' of mathematics (Hurst \& Hurrell, 2014; Siemon, Bleckley, \& Neal, 2012) and is a complex set of connected mathematical ideas. It has been defined by (Hurst, 2017) with the definition based on earlier work by Siemon et al. (2006) and Siemon, Bleckley, \& Neal (2012). Multiplicative thinking is characterised by the capacity to:

- Work flexibly with a wide range of numbers including very large and small whole numbers, decimals, fractions, ratio and percentage

- Work conceptually with the relative magnitude of whole and decimal numbers in a range of representations, demonstrating an understanding of the notion of 'times as many'

- Demonstrate a conceptual understanding of the multiplicative situation, the relationship between multiplication and division, numbers of equal groups, factors and multiples, and the various properties of multiplication

- Articulate a conceptual understanding of a range of multiplicative ideas in a connected way with explicit language and terminology.

This study is particularly concerned with aspects of each of the dot points. That is, to see numbers in flexible ways through partitioning, demonstrate an understanding of the relative magnitude of numbers with respect to place value, and use manipulatives in the form of bundling sticks to articulate an understanding of the concepts of equal groups and the relationship between multiplication and division.

\section{Multiplication and Division - The Inverse Relationship}

Jacob and Mulligan (2014) and Hurst (2015) discussed the importance of considering the 'multiplicative situation' and seeing multiplication and division together, rather than as separate processes. That is, the three quantities - number of groups, number in each group, and total - can be used to consider a multiplication problem and its inverse that is division. Hurst (2015, p. 11) pointed out the following - "If we know the group size and the number of groups, we multiply. If we know the total amount and one of the other quantities, we divide to find the one we don't know". Hence, an array with five rows of three can be used to describe a multiplication situation of $5 \times 3=15$ but can be used equally well to describe the inverse situation of $15 \div 5=3$, where the total of fifteen is split into five equal groups of three (Hurst, 2015).

Downton (2013, p. 242) stated that, "The notion that division of whole numbers can be interpreted in two different ways reflects its relationship to multiplication, namely division by the multiplier (partitive model) and division by the multiplicand (quotitive model)". She described partitive division in terms of knowing the number of equal parts but not the size of the parts, and quotitive division as knowing the size of the equal parts but not how many parts there are. Downton (2013, p. 242) suggested that children needed "to develop their conceptual understanding of the multiplicative relationships inherent in a problem" through working with a range of problem types, and that it was important to teach division alongside multiplication, not after it. Ultimately, Downton (2013, p. 242) saw the conceptual understanding of division and its inverse relationship with multiplication as being more important than "whether a task involves partitive or quotitive division".

\section{Manipulatives and Multiplicative Thinking}

Various researchers have discussed the use of manipulatives to develop multiplicative concepts. Jacob and Mulligan (2014) describe how the multiplicative array is an ideal representation for the notion of equal groups as it can show the three quantities involved - number of groups, number in each group, and product - at the same time. Arrays can be made with manipulatives such as counters or tiles. Siemon et al. (2015) discuss the development of early place value knowledge through the use of bundling sticks or stacks of cubes. They note the importance of counting such bundles, not in terms of 'ten, twenty, thirty' etc., but 'one ten, two tens' etc. as, "it is important to emphasise the count of tens" (Siemon et al., 2015, p. 297).

As noted earlier in this discussion, it is the way in which manipulatives are used, not merely that they are used. Askew noted the importance of assisting children to move 'from using them as models of to being models for and then to becoming tools for thinking with' (Askew, 2016, p. 139). To do this, teachers need to make the connections between the mathematical structure and the manipulative explicit for children, whether the manipulative/s be 
counters or tiles forming an array, bundling sticks or cube stacks to demonstrate partitioning, or other manipulatives.

The proposition is that if students know about partitioning based on place value and have developed a knowledge of the distributive property of multiplication and numbers of equal groups through the use of the array, they are in a position to learn about the grid method of multiplication, and consequently, the standard multiplication algorithm. Similarly, if they have a conceptual understanding of the multiplicative situation based on numbers of equal groups, they better placed to learn about the splitting of quantities and eventually represent this as a division algorithm. As noted earlier, the notion that manipulatives could be used to develop an understanding of multiplicative concepts was of interest. In particular, the study reported on here is particularly concerned with an understanding of multiplication and division.

\section{Research Questions}

The following research questions were posed:

- What processes do primary and middle school children use for multiplication and division?

- Do primary and middle school children use place value partitioning for multiplication and division?

- Are primary and middle school students able to explain the processes of multiplication and division through the use of manipulatives such as bundling sticks?

\section{METHODOLOGY}

The use of manipulatives in mathematics teaching, in particular for the teaching of multiplicative concepts, has been discussed in the previous section. The study reported on here is part of a large on-going project on multiplicative thinking that has involved teachers and their students aged between nine and thirteen years from schools in Western Australia, New Zealand, and the United Kingdom. This particular part of the study was conducted to find out the extent to which a sample of primary and middle school students knew about the processes of multiplication and division, and if they were able to explain their thinking with the use of manipulatives.

A sample of 32 New Zealand students from Year 4 (six students), Year 5 (nine students), and Year 6 (17 students) were interviewed by the researchers. Interviews were conducted in the latter part of the school year, and children's ages ranged from nine to eleven years. Three or four students were selected from each of nine classes and they were identified by their class teachers as representing a cross section of mathematical ability. Interviews were audio recorded and manually transcribed. Photographs were taken of applicable work samples and/or use of manipulatives. Students were asked the following four questions:

1. Show me and/or tell me how you would work out the answer to $7 \times 15$.

2. Please show me with some of the bundling sticks what is happening in the working out that you explained/showed me.

3. Show me and/or tell me how you would work out the answer to $90 \div 7$.

4. Please show me with some of the bundling sticks what is happening in the working out that you explained/showed me. [* Students who were unable to work with the numbers in Questions 1 and 3 were given 'easier questions with single digits to eliminate the possibility that the size of the numbers had an impact on their capacity to complete the task.]

Bundling sticks were used in the study to facilitate children's ability to demonstrate their understanding of place value, which is closely linked to multiplicative thinking. The ability to multiply and divide with numbers greater than one digit necessitates an understanding of place value. Specifically, children needed to make the conceptual link between a bundle/s of ten sticks and the tens digit in the numbers 15 (the multiplication question) and 90 (in the division question). The multiplicand 15 was chosen for the multiplication problem because children were likely to know the multiplication facts for five and so lack of known facts would be unlikely to be a distractor. Bundling sticks (popsicle sticks) were provided in pre-bundled sets of ten and as single sticks. They were used in preference to Multi-base Arithmetic Blocks (MABs) as the bundles can be easily split and re-grouped. Van de Walle et al. (2013, p. 195) noted that "put-together-take-apart" models such as bundling sticks "most clearly reflect the relationship of ones, tens, and hundreds [because] the ten can actually be made or grouped from the single pieces". They also said that pre-made bundles of ten provide a good transition to pre-grouped models like MABs. In New Zealand, the second tier curriculum material places an emphasis on children grouping physical objects to make ten, and suggests bundling sticks or containers of plastic beans. The division question may appear difficult but 
bundling sticks were used to facilitate children's chances of understanding and demonstrating the remainder in the answer. If an easier task had been used a child might have known there would be a remainder because the dividend was not an answer to a known multiplication fact. As it transpired, some children were able to demonstrate the remainder and some could not do so. (Siemon, et al., (2015) also noted the importance of bundling sticks as children need the physical experience of making up the bundles of ten, and moving to the pre-grouped MABs too soon can cause confusion for some children. Bundling sticks have a high 'epistemic fidelity'. (Siemon, et al., 2015, p. 110) describe 'epistemic fidelity' as

"the measure of the quality of the mapping between the material's features and the target knowledge domain. If this mapping is strong, the model is often termed transparent as it allows students to 'see through it' to the underlying mathematics".

\section{RESULTS}

\section{Multiplication $7 \times 15$}

The results for Question 1 - Show me and/or tell me how you would work out the answer to $7 \times 15-$ are presented here in Table 1.

Table 1. Summary of responses to Question 1

\begin{tabular}{|c|c|c|c|c|}
\hline \multirow{2}{*}{\multicolumn{5}{|c|}{$\begin{array}{l}\text { Response and frequency by year level } \\
\text { Completely demonstrated knowledge of the multiplication process (19) }\end{array}$}} \\
\hline & & & & \\
\hline Correctly used part products $7 \times 10$ and $7 \times 5$ based on place value partition & 18 & 1 & 6 & 11 \\
\hline Correctly used different part products $-7 \times 12$ and $7 \times 3$ & 1 & & 1 & \\
\hline \multicolumn{5}{|l|}{ Partially demonstrated knowledge of the multiplication process (6) } \\
\hline Used an additive strategy to work out the answer & 3 & 3 & & \\
\hline Used an appropriate alternative strategy to work out the answer & 3 & & 1 & 2 \\
\hline $\begin{array}{l}\text { Unable to demonstrate knowledge of the multiplication process (7) } \\
\text { Unable to work out the answer to } 7 \times 15\end{array}$ & 7 & 2 & 1 & 4 \\
\hline
\end{tabular}

Over half of the students who correctly used the standard partition or part products were able to work out the answer mentally. When they were asked to explain how they arrived at the answer, most showed something similar to $\operatorname{Kim}($ Year 5) and Tom (Year 6).
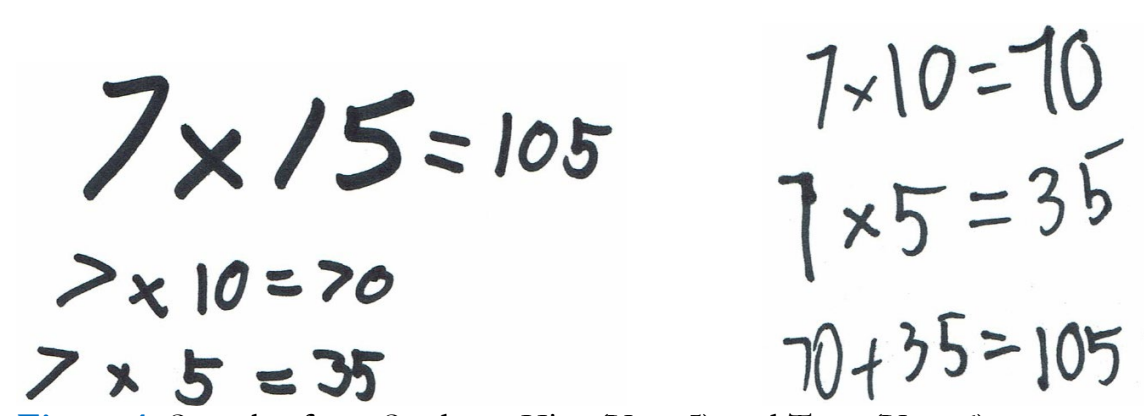

Figure 1. Samples from Students Kim (Year 5) and Tom (Year 6)

Only one student wrote the standard vertical multiplication algorithm and one other said that she visualised it in her head.

In Question 2, students were asked - Please show me with some of the bundling sticks what is happening in the working out that you explained/showed me. The responses are compiled here in Table 2 . There are several categories of student responses ranging from completely representing the multiplication process to being unable to use the bundling sticks. 
Table 2. Summary of responses to Question 2

\begin{tabular}{|c|c|c|c|c|}
\hline Responses and frequency by year level & All & Y4 & Y5 & Y6 \\
\hline \multicolumn{5}{|l|}{ Completely represented the multiplication process (11) } \\
\hline $\begin{array}{l}\text { Showed } 7 \text { groups of } 15 \text { ( } 1 \text { ten and } 5 \text { singles), grouped the } 7 \text { tens as } 70 \text { and the } 7 \\
\text { fives as } 35 \text {, before regrouping the } 35 \text { as tens and singles }\end{array}$ & 10 & & 3 & 7 \\
\hline Made a $7 \times 15$ array & 1 & & 1 & \\
\hline \multicolumn{5}{|l|}{ Partially represented the multiplication process (6) } \\
\hline $\begin{array}{l}\text { Did not make } 7 \text { groups of } 15 \text {. Made bundles of answers to partial products only. } \\
\text { Did not combine partial products. }\end{array}$ & 2 & 1 & 1 & \\
\hline Showed 7 groups of 15 but did not physically combine and regroup them & 4 & 1 & 1 & 2 \\
\hline \multicolumn{5}{|l|}{ Incorrectly represented the multiplication process (1) } \\
\hline $\begin{array}{l}\text { Made bundles of only the two factors (i.e., they made a group of } 7 \text { and a group of } \\
\text { 15) }\end{array}$ & 1 & & & 1 \\
\hline \multicolumn{5}{|l|}{ Unable to use the bundling sticks (14) } \\
\hline Not able to use the bundling sticks in a meaningful way, despite prompting & 14 & 4 & 3 & 7 \\
\hline
\end{tabular}

It can be seen that there is much wider range of responses to Question 2 than for Question 1. Only ten students represented the multiplication process by showing seven groups of 15 , combining the seven ten bundles and the seven bundles of five, before regrouping the fives as tens and showing the total. This reflects the partial product method and also the algorithm. Typical samples of a student's work in completely representing the process is shown in Figure 2. Lisa (Year 5) made the seven groups of 15 (picture 1 in Figure 2), then put the seven bundles of 10 together (picture 2 in Figure 2) and finally regrouped the 35 bundle into three tens and five singles (picture 3 in Figure 2).
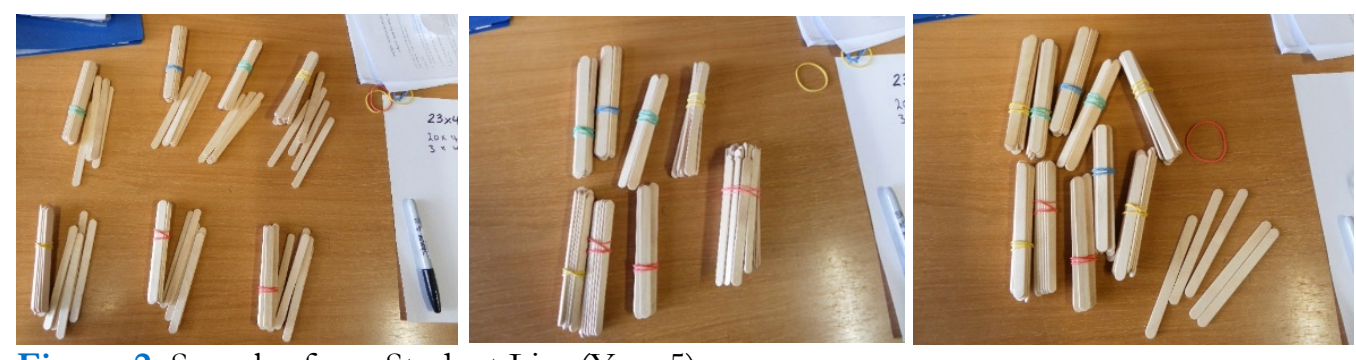

Figure 2. Samples from Student Lisa (Year 5)

Figure 3 contains some examples of how some students used the bundling sticks incorrectly. Tyler (Year 4) was able to work out the answer for $7 \times 15$ by using partial products of $7 \times 10$ and $7 \times 5$ (in Question 1 ) but when he used the bundling sticks he made only groups of sticks to represent the factors - that is, groups of 7,10 , 7 and 5 (picture 1 in Figure 3). Joss (Year 5) was unable to solve $7 \times 15$ and was asked to work out $4 \times 14$ to see if different numbers would enable him to complete the task. He used the sticks to show the factors of 4 and 14 (see picture 2 in Figure 3). Rowan (Year 6) was also unable to work out $7 \times 15$ and was asked to show $4 \times 5$ with bundling sticks (see picture 3 in Figure 3). Rowan was given the 'easier' question to find out if it were the sizes of the numbers in $7 \times 15$ that were causing him difficulty. However, there appears to be no knowledge of the concept of numbers of equal groups with the three students whose responses appear in Figure 3.
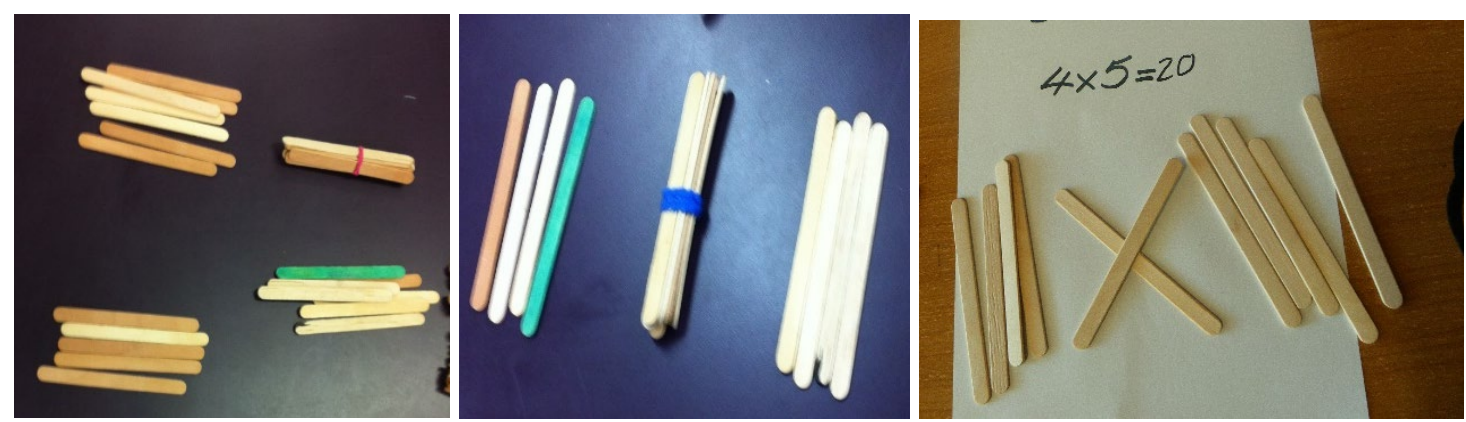

Figure 3. Samples from Students Tyler (Year 4), Joss (Year 5), and Rowan (Year 6)

A comparison of responses to Questions 1 and 2 about the multiplication of 7 by 15 also provokes some useful discussion. As is seen from Tables 1 and 2, 19 students responded correctly to Question 1 by using a partial product strategy or a viable alternative. However, only ten were able to use the bundling sticks to completely represent the multiplication process, that is, by showing seven groups of 15 , combining the seven bundles of ten 
and the seven bundles of five, before regrouping the fives as tens and showing the total. One student made a 7 by 15 array, which although correct, is different to depicting seven bundles of fifteen. Six other students partially represented the multiplication with bundling sticks. Four of them made seven groups of fifteen and two made bundles of parts products but none physically combined or re-grouped the bundling sticks.

In seeking a reason/s for the fact that only eleven students were able to fully represent the multiplication process with the sticks, it is tempting to conclude that it is due to their lack of familiarity with the bundling sticks. Both researchers who worked on this study commented that many of the students who were interviewed seemed uncomfortable about using the bundling sticks and many took a long time in coming to terms with what to do with them. They did not seem to connect what they had said when explaining how they solved $7 \times 15$ with the physical representation of it. This supports the comments reported earlier by Baroody (1989), Ball (1992), Boggan et al. (2010), and Carbonneau et al. (2013), that teachers need to be explicit about helping their students to make the connection between the concept and the manipulative. Although it might be expected that students had worked with concrete materials before using the formal algorithm, our results suggest that this may not have happened. It is encouraging that the majority of students were able to use partial products based on place value partitioning to work out the answer to $7 \times 15$ as this situates them well to understand the distributive property, the grid method for multiplication, and later, the vertical multiplication algorithm. However, to really consolidate their knowledge, it is important that they are able to translate their use of partial products in terms of a physical representation. They needed to show the seven groups of ten and the seven groups of five, combine them into groups of 70 and 35 , then regroup the 35 into three tens and five, and finally to make a bundle of ten tens and five singles to show the answer of 105. Six students did this partially which suggests that their knowledge of the multiplication process is not sufficiently robust, perhaps because they have not been accustomed to using bundling sticks. Indeed, nearly half of the students were not able to use the bundling sticks to show seven groups of fifteen.

\section{Division $90 \div 7$}

Responses to Question 3 - Show me and/or tell me how you would work out the answer to $90 \div 7$ - are contained in Table 3.

Table 3. Responses to Question 3

\begin{tabular}{|c|c|c|c|c|}
\hline Responses and frequency by year level & All & Y4 & Y5 & Y6 \\
\hline \multicolumn{5}{|l|}{ Completely demonstrated knowledge of the division process (7) } \\
\hline $\begin{array}{l}\text { Obtained correct answer of } 12 \text { remainder } 6 \text { having used a strategy starting with a } \\
\text { split of } 90 \text { into } 7 \times 10 \text {, and then splitting the remaining } 20\end{array}$ & 6 & & 2 & 4 \\
\hline $\begin{array}{l}\text { Obtained correct answer after re-writing the example as a multiplication sentence } \\
7 \times \ldots=90\end{array}$ & 1 & & & 1 \\
\hline Partially demonstrated knowledge of the division process (4) & & & & \\
\hline $\begin{array}{l}\text { Indicated that } 90 \div 7 \text { required splitting } 90 \text { into seven groups but was unable to } \\
\text { complete the working out }\end{array}$ & 4 & & 1 & 3 \\
\hline $\begin{array}{l}\text { Unable to demonstrate knowledge of the division process (21) } \\
\text { Unable to work out } 90 \div 7 \text { in any way }\end{array}$ & 21 & 6 & 6 & 9 \\
\hline
\end{tabular}

Cam (Year 6) explained his thinking in this way - " 7 times 10 is 70 and 7 times 2 is 14, and there would have to be six left over. It would be $12 \ldots$ but there are 6 left over . . I I don't know how to write that". Maxine (Year 6 ) showed some sound reasoning and perseverance during this exchange with the interviewer:

MAXINE: I haven't done anything like this before.

INT: OK, so when you see 90 divided by 7 , what is it asking you to do, do you think?

MAXINE: It's like seven times what equals ninety - she then wrote down ...

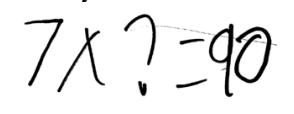

INT: Any idea how you might do that?

MAXINE: Well 7 times 12 is . . 84, so 7 times 13 would be . . 91, so . . it's more than 90 so it probably wouldn't be a whole number... Twelve times . . . and six more makes 90

Responses to Question 4 - Please show me with some of the bundling sticks what is happening in the working out that you explained/showed me - are contained in Table 4. As with Question 2, there are several categories of responses to this question - completely representing the division process with bundling sticks, partially doing so, and being unable to do so. 
Table 4. Responses to Question 4

\begin{tabular}{|c|c|c|c|c|}
\hline Responses and frequency by year level & All & Y4 & Y5 & Y6 \\
\hline \multicolumn{5}{|l|}{ Completely represented the division process $(8)$} \\
\hline $\begin{array}{l}\text { Collected } 9 \text { bundles of } 10 \text {, made } 7 \text { shares of } 10 \text {, and split the remaining } 20 \text { into } \\
\text { seven shares of two sticks, with } 6 \text { left over }\end{array}$ & 8 & & 2 & 6 \\
\hline \multicolumn{5}{|l|}{ Partially represented the division process (1) } \\
\hline $\begin{array}{l}\text { Made } 7 \text { groups of } 10 \text { and split the remaining } 20 \text { sticks but didn't make all groups } \\
\text { the same and didn't have a remainder }\end{array}$ & 1 & & 1 & \\
\hline \multicolumn{5}{|l|}{ Unable to use the bundling sticks (23) } \\
\hline Unable to use the bundling sticks in any meaningful way, despite prompting & 23 & 6 & 6 & 11 \\
\hline
\end{tabular}

When comparing the responses to Questions 3 and 4, some very interesting observations can be made. Of the seven students who obtained a correct answer for Question 3, only one of them, Cam (Year 6), also correctly represented the division process with the bundling sticks. It is possible that the other six students who were unable to use the bundling sticks did not have a robust knowledge of the division process and had possibly learned it in a procedural way. However, eight of the students who did not obtain a correct answer for Question 3, were able to correctly represent the division process in Question 4. It is possible that the bundling sticks enabled those eight students to organize their thinking and to understand exactly what was happening in the division or sharing process. Some of their responses follow here beginning with Lyle (Year 5).

Lyle (Year 5) counted out seven of the ten bundles and then said, "Now what do you do with these ones? [i.e., the last two ten bundles] . . . you have to divide the twenty between the seven groups. You could try three ... [He counted out the sticks and got to the last group] . . . but then you have that" [not enough to go round]. [See his arrangement in Figure 4]

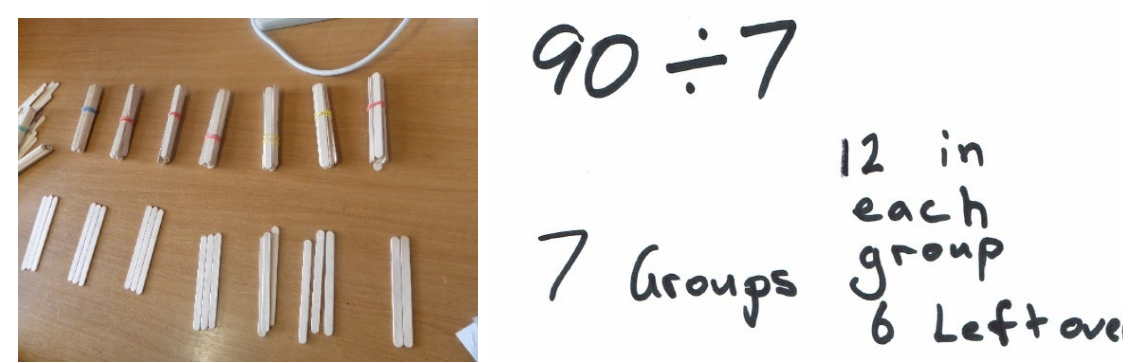

Figure 4. Sample from Student Lyle (Year 5)

INT: What do the groups have to be?

LYLE: "They have to be even ... I put too many in". He counted out seven and allocated one to each group and repeated the process and had six left over. LYLE recorded it as above.

Sally (Year 5) was also unable to work out the answer to $90 \div 7$ but did so when using the bundling sticks. Following is the conversation between Sally and the interviewer. Figure 5 contains her work samples.
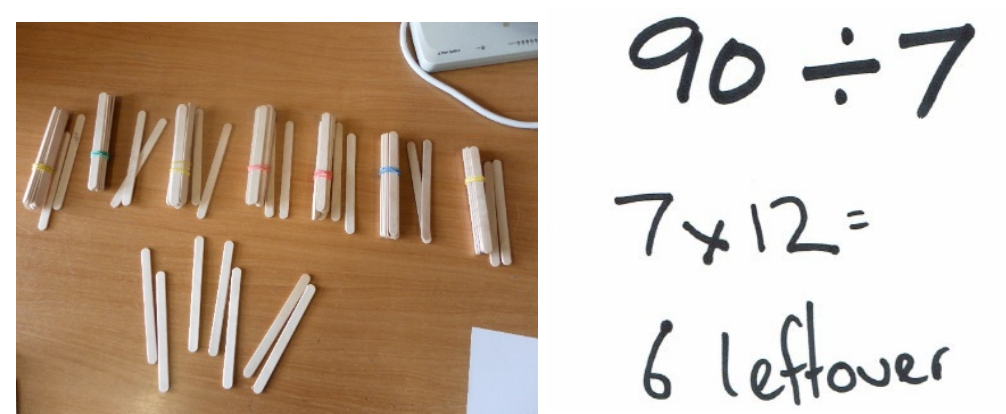

Figure 5. Samples from Student Sally (Year 5)

SALLY made seven groups with a bundle of ten in each group.

INT: What are you going to do with the others?

SALLY: "I'd probably split them up. I'd just keep adding the sticks to the groups". SALLY shared the single sticks into the seven groups

INT: What's happened?

SALLY: "We're one short". 
INT: What's important about the seven groups?

SALLY: "They have to be even". [See Figure 5]

INT: How many are there in each group now?

SALLY: “There's 12". SALLY recorded the division on her work sample, as above.

Zac (Year 6) also had difficulty with $90 \div 7$, as the following conversation shows. However, when he used the bundling sticks, he was able to work out the answer. Figure 6 shows his work samples. The first picture shows the unfinished array that he drew initially.

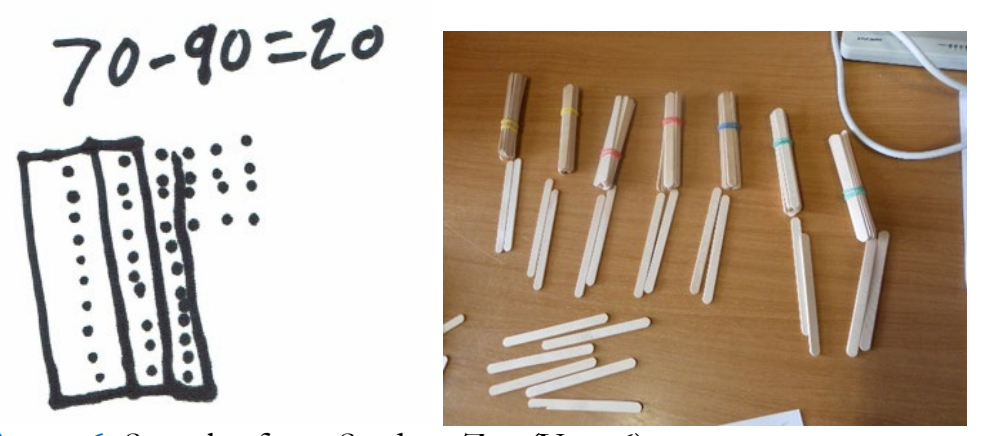

Figure 6. Samples from Student Zac (Year 6)

Zac drew an array of sorts [See sample] He then wrote 70-90=20 and said "You can't do it, because ... if there was one added to the 90 , you could do it because it would be even".

INT: So what's this actually asking you to do?

ZAC: "Divide it into seven groups". He selected 9 bundles of ten and shared them into seven sets of ten and had 20 left over.

INT: What are you going to do with the 20? ZAC unbundled the two sets of ten and counted them out one by one to give equal groups of 12 and 6 left over [See Figure 6].

It seems that a combination of discussion and questioning from the interviewer and the availability of the bundling sticks assisted Lyle, Sally, and Zac to more clearly understand the division process, which they were unable to do initially. This supports the comments made by Delaney (2010) and Van de Walle et al. (2013) about the use of dialogue in association with manipulatives. Also, they demonstrated that they do understand the notion of numbers of equal groups, depending on the situation and context. It is also worth noting that Zac attempted to solve for $90 \div 7$ by drawing an array and it would have been interesting had he continued that to its conclusion.

With regard to the six students who correctly answered Question 3 (work out the answer for $90 \div 7$ ), but could not use the bundling sticks to demonstrate it, there is perhaps one clue in one student's response as to why they were unable to use the bundling sticks. Kal (Year 6) appeared very capable and almost instantaneously gave the answer for Question $1(7 \times 15)$ and Question $3(90 \div 7)$. When asked to use the sticks, Kal said, "I don't know. I've never worked with sticks before". It is possible that Kal, and perhaps others in the group, had learned to calculate examples like those in Questions 1 and 3 in a procedural way as they do not seem to understand at a conceptual level about numbers of equal groups.

\section{DISCUSSION OF FINDINGS}

There are several points to emerge from the data for this short study. First, the majority of the participants $(78 \%)$ were able to calculate for $7 \times 15$ but only $34 \%$ could do so for $90 \div 7$. It is surprising that the difference is as great as it is, given that multiplication and division are the inverse of one another. Indeed, only one student (Maxine) identified that when working out the answer for the division example. This seems to indicate that students have been taught a process for multiplying a one-digit and two-digit number but have not been taught how to divide a two-digit number by a one-digit number. This conjecture is supported by the observation that most of the students who were interviewed were clearly uncomfortable with the use of bundling sticks. Had they been used to manipulating bundling sticks, accompanied by some explicit teaching, they may have been able to see the connection that exists between multiplication and division and that it is based on the number of equal groups. In the case of the multiplication example $(7 \times 15=105)$, that would have been manifest as $15 \times 7=105$ (commutative property) but also as $105 \div 7=15$ and $105 \div 15=7$. 
Second, $59 \%$ of the participants used a partial product strategy to calculate the answer for $7 \times 15$. Most used $(7 \times 10)+(7 \times 5)$ based on place value partitioning. However, as shown in Table 2 , only $34 \%$ were able to use the bundling sticks to fully demonstrate the multiplication process. It seems clear that they have not made the connection between the physical representation provided by the bundling sticks and the concept of partial products or the distributive property. There are two points to consider here - one is that the students have probably not had much exposure to bundling sticks to build knowledge of the processes of multiplication and division, as suggested above. The second is the power of bundling sticks to identify students who do not have a robust knowledge of the multiplication and division processes and the relationship between them.

Third, student responses to the use of bundling sticks for Question 4 has created something of a dilemma. Five of the seven students who actually obtained the correct answer for Question 3 (12 remainder 6) were unable to demonstrate the process using the bundling sticks. It may be that the students who obtained the correct answer but couldn't demonstrate with the bundling sticks, were unfamiliar with using the bundling sticks. On the other hand, eight of the students who did not arrive at the answer of 12 remainder 6 for Question 3, were able to demonstrate the division process using the bundling sticks. It appears as if the bundling sticks facilitated the development of knowledge for some students but not for others. As suggested earlier, perhaps the students who were unable to demonstrate the division process with the bundling sticks held a very procedural view of it. Also, for Questions 3 and 4, only 34\% of students were able to provide the answer for $90 \div 7$ or suggest it required 90 being split into seven groups and only $28 \%$ could use bundling sticks to completely or partially represent the division process.

It appears that the majority of students $(59 \%)$ calculated the answer for $7 \times 15$ using partial products and also either completely or partially demonstrated the multiplication process with the bundling sticks. This appears to place them in a good position for learning about grid multiplication and later, the vertical multiplication algorithm. Grid multiplication is developed by combining the array and the distributive property and is an important precursor for understanding the written multiplication algorithm (Hurst \& Hurrell, 2018a). Initially, an array for a twodigit by one-digit example is used (e.g., $7 \times 15)$ based on standard place value partitioning and then a two-digit by two-digit example can be developed as the foundation for the written algorithm (Hurst \& Hurrell, 2018b). However, the concept of splitting quantities into numbers of equal groups does not appear to be as well understood. Hence, it is unlikely that the students in this sample have sufficient conceptual understanding to learn about an algorithm for division.

With regard to the responses by year level, the majority of students in each year level were able to demonstrate or partially demonstrate the multiplication process (Question 1) in terms of part products or an alternative strategy. However, a minority of Year 4 students could demonstrate the process using bundling sticks (Question 2) whilst approximately half of the Year 5 and Year 6 students could do so. For the division question (Question 3), no Year 4 student could demonstrate the process, and a minority of year 5 and Year 6 students could do so. This pattern was the same for the use of bundling sticks to represent the division process (Question 4) where no Year 4 student could do so, and a clear minority of Year 5 and Year 6 students could do so. This raises an interesting issue. It might generally have been expected that students in Year 4 might be more familiar with the use of bundling sticks than students in Years 5 and 6 yet a greater proportion of students in the latter year levels were able to appropriately use the bundling sticks.

\section{CONCLUSIONS AND IMPLICATIONS}

It needs to be stated at the outset that the number of participants in the sample was relatively small and therefore it is not appropriate to claim that any major generalisations can be made on the basis of these results. Nonetheless, observations suggest that similar research with a larger student sample is worth pursuing.

The research questions for the study were as follows:

- Research Question 1: What processes do primary and middle school children use for multiplication and division?

- Research Question 2: Do primary and middle school children use place value partitioning for multiplication and division?

- Research Question 3: Are primary and middle school students able to explain the processes of multiplication and division through the use of bundling sticks?

In terms of these research questions, the following can be said:

The majority of students in the sample demonstrated knowledge of partial products based on place value partitioning and were able to solve the multiplication example in that way. However, a large proportion of these 
successful students were not able to demonstrate the multiplication process using the bundling sticks. It is reasonable to suggest that they may have procedural knowledge rather than conceptual knowledge of multiplication. Only a minority of students could solve the division example suggesting that perhaps the connection between multiplication and division has not been made explicitly clear to them. Furthermore, only one of these successful students correctly represented the division process with the bundling sticks, again suggesting procedural rather than conceptual knowledge.

There are several implications to emerge from this study. The power of manipulatives such as bundling sticks is clear, both as a tool for teaching conceptually and as an assessment resource for quickly identifying whether or not students have a conceptual understanding. However, the results from the study seem to indicate that the participants were uncomfortable and unfamiliar with using bundling sticks. Our study provided little indication of children having learned multiplicative concepts through use of manipulatives in their instruction. As was suggested in the literature review (Puchner et al., 2010; Swan \& Marshall, 2010; Furner \& Worrell, 2017), teachers should consider manipulatives as a powerful tool for teaching concepts and regard them as much more than a motivational aid, or to add a dimension of 'fun' to mathematics lessons. They are clearly more than the latter and targeted professional learning in the use of manipulatives is likely to be of assistance to teachers. Professional learning for teachers could be based around the principles for manipulative use developed by Laski et al. (2015) and incorporate training in specific pedagogies for manipulative use including how to incorporate effective discussion, questioning, and demonstration (Delaney, 2010; Swan \& Marshall, 2010). These principles could be used to develop a sound understanding of the standard multiplication algorithm from children's use of arrays.

Baroody (1989), Ball (1992), and Ma (1999) all made some evocative statements about the use of manipulatives and these were reported in the literature review. Clearly, there are no guarantees with using manipulatives, they do not magically lead children to mathematical learning, and their use requires careful direction by the teacher. More importantly, teachers need to familiarise themselves with just how manipulatives can be effectively harnessed to help students develop a deep knowledge of multiplicative concepts.

\section{REFERENCES}

Askew, M. (2016). Transforming primary mathematics: Understanding classroom tasks, tools and talk. Oxon: Routledge. https://doi.org/10.4324/9781315667256

Ball. D. L. (1992). Magical hopes: Manipulatives and the reform of math education. American Educator: The Professional Journal of the American Federation of Teachers, 16(2), 14-18, 46-47.

Baroody, A. J. (1989). Manipulatives don't come with guarantees. The Arithmetic Teacher, 37(2), 4-5.

Boggan, M., Harper, S., and Whitmire, A. (2010). Using manipulatives to teach elementary mathematics. Journal of Instructional Pedagogies, 3, 1-6. Retrieved from: http://www.aabri.com/manuscripts/10451.pdf

Carbonneau, K. J., Marley, S. C., and Selig, J. P. (2013). A meta-analysis of the efficacy of teaching mathematics with concrete manipulatives. Journal of Educational Psychology, 105(2), 380-400. https://doi.org/10.1037/a0031084

Cope, L. (2015). Math manipulatives: Making the abstract tangible. Delta Journal of Education, 5(1), 10-19. Retrieved from: http://www.deltastate.edu/PDFFiles/DJE/spring-2015/dje_spring_2015_cope-final.pdf

Delaney, K. (2010). Making connections: Teachers and children using resources effectively. In I. Thompson (Ed.), Issues in teaching numeracy in primary school, (2nd ed.). Maidenhead: Open University Press.

Devlin, K. (2008). It ain't no repeated addition. Retrieved from: http://www.maa.org/external_archive/devlin/ devlin_06_08.html

Downton, A. (2013). Making connections between multiplication and division. In V. Steinle, L. Ball, and C. Bardini (Eds), Mathematics education: Yesterday, today and tomorrow (Proceedings of the $36^{\text {th }}$ annual conference of the Mathematics Education Research Group of Australasia, pp. 242-249). Melbourne, Victoria: MERGA.

Furner, J. M., and Worrell, N. L. (2017). The importance of using manipulatives in teaching math today. Transformations, 3(1), 1-24.

Hiebert, J. (1999). Relationships between research and the NCTM standards. Journal for Research in Mathematics Education, 30(1), 3-19. https://doi.org/10.2307/749627

Hurst, C. (2015). The multiplicative situation. Australian Primary Mathematics Classroom, 20(3), 10-16.

Hurst, C. (2017). Children have the capacity to think multiplicatively, as long as . . European Journal of STEM Education, 2(3), 7-20. https:// doi.org/10.20897/ ejsteme/78169

Hurst, C., and Hurrell, D. (2014). Developing the big ideas of number. International Journal of Educational Studies in Mathematics, 1(2), 1-18. https://doi.org/10.17278/ijesim.2014.02.001

Hurst, C., and Hurrell, D. (2018a). Algorithms are useful: Understanding them is even better. Australian Primary Mathematics Classroom, 23(3), 17-21. 
Hurst, C., and Hurrell, D. (2018b). Algorithms are great: What about the mathematics that underpins them? Australian Primary Mathematics Classroom, 23(3), 22-26.

Jacob, L., and Mulligan, J. (2014). Using arrays to build multiplicative thinking in the early years. Australian Primary Mathematics Classroom, 19(1), 35-40.

Laski, E., Jor'dan, J. R., Daoust, C., and Murray, A. K. (2015). What makes mathematics manipulatives effective? Lessons from cognitive science and Montessori education. https:/ / doi.org/10.1177/2158244015589588

Ma, L. (1999). Knowing and teaching elementary mathematics. Mahwah, NJ: Lawrence Erlbaum Associates.

Mason, J., Stephens, M., and Watson, A. (2009). Appreciating mathematical structure for all. Mathematics Education Research Journal, 21(2), 10-32. https://doi.org/10.1007/BF03217543

Perry, B., and Howard, P. (1994). Manipulatives: Constraints on construction? In G. Bell, B. Wright, N. Leeson, and J. Geeke (Eds.), Challenges in mathematics education: Constraints on construction (Proceedings of the 17th annual conference of the Mathematics Education Research Group of Australasia, 487-495). Lismore, NSW: MERGA.

Perry, B., and Howard, P. (1997). Manipulatives in primary mathematics: Implications for learning and teaching. Australian Primary Mathematics Classroom, 2(2), 25-30.

Pesek, D. D., and Kirshner, D. (2000). Interference of instrumental instruction in subsequent relational learning. Journal for Research in Mathematics Education, 31, 524-540. https://doi.org/10.2307/749885

Puchner, L., Taylor, A., O’Donnell, B., and Fick, K. (2010). Teacher learning and mathematics manipulatives: A collective case study about teacher use of manipulatives in elementary and middle school mathematics lessons. School Science and Mathematics, 108(7), 313-325. https://doi.org/10.1111/j.1949-8594.2008.tb17844.x

Reys, R. E., Lindquist, M. M., Lambdin, D. V., Smith, N. L., Rogers, A., Falle, J., Frid, S., and Bennett, S. (2012). Helping children learn mathematics. (1st Australian Ed.). Milton, Qld: John Wiley \& Sons, Australia.

Roberts, S. (2007). Not all manipulatives and models are created equal. Mathematics Teaching in the Middle School, 13(1), 6-9.

Siemon, D., Beswick, K., Brady, K., Clark, J., Faragher, R., and Warren, E. (2015). Teaching mathematics: Foundations to middle years. $\left(2^{n d} \mathrm{Ed}\right.$.). South Melbourne: Oxford.

Siemon, D., Bleckly, J., and Neal, D. (2012). Working with the Big Ideas in Number and the Australian Curriculum: Mathematics. In B. Atweh, M. Goos, R. Jorgensen, and D. Siemon, (Eds.), Engaging the Australian National Curriculum: Mathematics - Perspectives from the Field. Online Publication: Mathematics Education Research Group of Australasia pp. 19-45.

Siemon, D., Breed, M., Dole, S., Izard, J., and Virgona, J. (2006). Scaffolding Numeracy in the Middle Years - Project Findings, Materials, and Resources, Final Report submitted to Victorian Department of Education and Training and the Tasmanian Department of Education, Retrieved from http://www.eduweb.vic.gov.au/edulibrary/ public/teachlearn/student/snmy.ppt

Skemp, R. (1976). Relational and instrumental understanding. Mathematics Teaching in the Middle School, 12(2), 88-95.

Swan, P., and Marshall, L. (2010). Revisiting mathematics manipulative materials. Australian Primary Mathematics Classroom, 15(2), 13-19.

Van de Walle, J. A., Karp, K. S., and Bay-Williams, J. M. (2013). Elementary and middle school mathematics: Teaching developmentally. (8th Ed.). Boston: Pearson

Wright, V. J. (2011). The development of multiplicative thinking and proportional reasoning: Models of conceptual learning and transfer. (Doctoral dissertation). University of Waikato, Waikato. Retrieved from https://researchcommons.waikato.ac.nz/handle/10289/5984. 